\title{
Structures of diamond tool composites
}

\author{
Struktury diamentowych kompozytów narzędziowych
}

\begin{abstract}
ANDRZEJ BAKOŃ ADAM BARYLSKI*
\end{abstract}

DOI: https://doi.org/10.17814/mechanik.2017.7.69

\begin{abstract}
Presented are structures and examples of applications of diamond tool composites. They are widely used as cutting tools, bonded abrasive tools and dressing tools.

KEYWORDS: diamond tool composites, cutting tools, bonded abrasive tools, dressing tools
\end{abstract}

Przedstawiono budowę i przykłady zastosowania diamentowych kompozytów narzędziowych. Są one szeroko używane w produkcji narzędzi skrawających, spojonych narzędzi ściernych i obciągaczy.

SŁOWA KLUCZOWE: narzędziowe kompozyty diamentowe, narzędzia skrawające, narzędzia ścierne, obciagacze

Of all known modern minerals diamond has the highest hardness and abrasion resistance [5-7]. It is noted for the highest values of compressive strength and Young's modulus. At the same time, the diamond has low friction coefficient compared to most of workpiece materials, what makes it a particularly valuable and extremely effective tool material.

Unfortunately, because of its reaction with iron and oxygen from ambient air, in processing of iron-based materials it is profitable to replace it with cubic boron nitride (CBN). Due to the mass character of production and the need to reduce costs, it is often profitable to use different types of diamond tools. In many cases, this is necessary due to the physicochemical properties of the workpiece materials [1-4]. Generally recommended for machining with diamond tools are: cemented carbides, glass, stones, ceramics, semiconductors, cermets, ferrites, PCD and PCBN materials, quartz, concretes, asphalts, etc. They are used also for non-ferrous ( $\mathrm{Ti}, \mathrm{Al}, \mathrm{Cu}, \mathrm{Mg}$ ) alloys, flame-sprayed metals.

\section{Diamond composites in application}

Diamond tools are composites of different structures. They can be grouped as follows:

- diamond cutting tools,

- diamond abrasive tools (grinding wheels and hones),

- diamond dressers,

- diamond lapping compounds.

To complement these groups are control and measurement diamond tools (e.g. tools for hardness measuring or for in-process active dimensional control) and diamond containing components of production machines, which should be particularly resistant to abrasion (e.g. steady rest).

According to the application requirements, composites may contain diamond crystals of different quality and vary-

\footnotetext{
* Dr Andrzej Bakoń (a.bakon@stegny.2a.pl) - Institute of Electronic Materials Technology; prof. dr hab. inż. Adam Barylski (abarylsk@ pg.gda.pl) - Gdańsk University of Technology, Faculty of Mechanical Engineering
}

ing in size [1]. Also varying may be the volume of diamonds. Grains may be or not oriented according to the optimum direction of diamond abrasion resistance. Therefore, many composite manufacturing methods are used. Next to diamond, composites also contain binder. The most practically significant ones use techniques, in which diamonds are combined by means of metals or their alloys, organic substances or ceramic materials.

\section{Composites used as cutting inserts and wear-resistant elements of machines}

Diamond composites used as working elements of cutting tools used to machine elements of engines, drive transmissions or abrasion-resistant elements (Fig. 1), are composed of a layer of fine diamond crystals, which is permanently connected with plate of tungsten carbide. They are nano- and microdiamond grains pressed and sintered under high pressure and elevated temperature conditions.

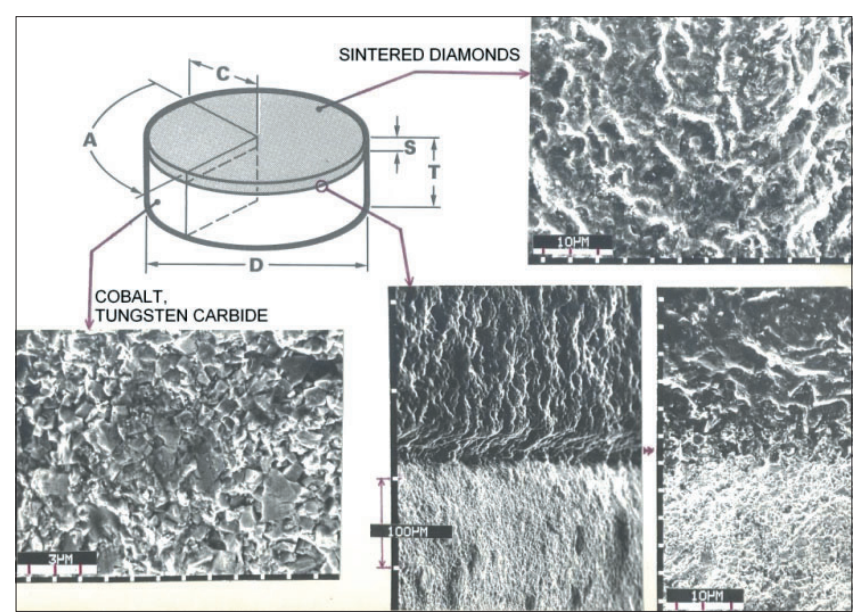

Fig. 1. PCD layer built materials and their structure

In this way, blanks can be manufactured, which are used directly in machining operations (cutting inserts, drill bits) and as abrasion-resistant elements, or as aggregate for the abrasive grains of desired size. In this type of layermaterials, so-called PCD (Polycrystalline Diamond), the bonding phase was initially cobalt, which has been made to penetrate between the diamond grains of the layer of tungsten carbide. The occurrence of metallic or carbide bonding phase and layered structure of composites caused these products to be mechanically resistant, but at the same time they are characterized by relatively low thermal resistance. There are several different process methods used to manufacture PCD materials. Beside cobalt, other infiltrators are used, especially those with thermal expansion coefficient similar to that of the diamonds, such as silicon and silicon carbide. 


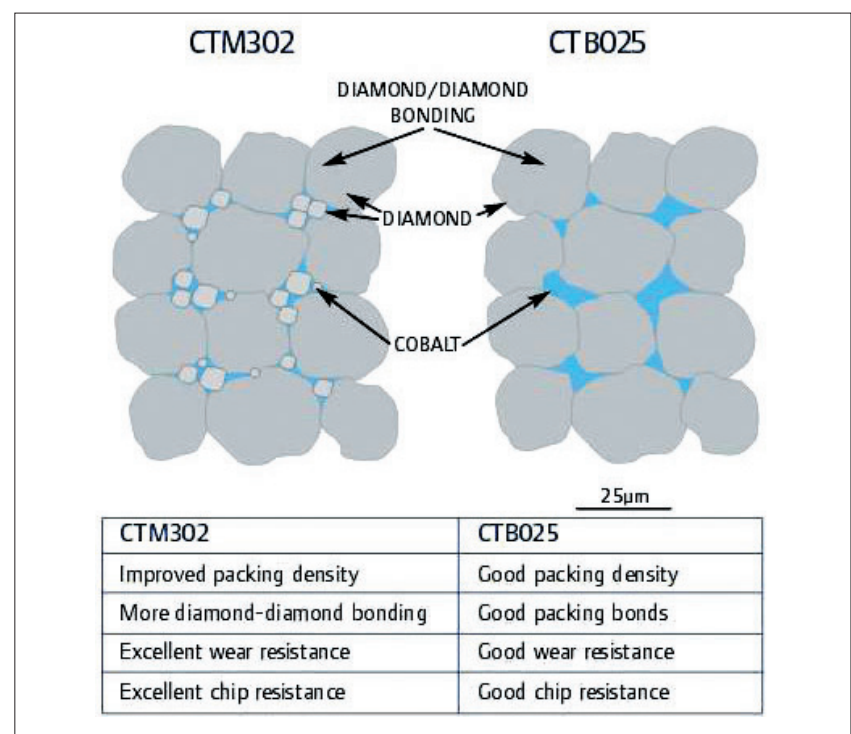

Fig. 2. Properties of PCD materials shown in relation to the size of the used diamond - by the example of two types of SYNDITE ${ }^{\text {TM }}$ material manufactured by Element 6 [11]

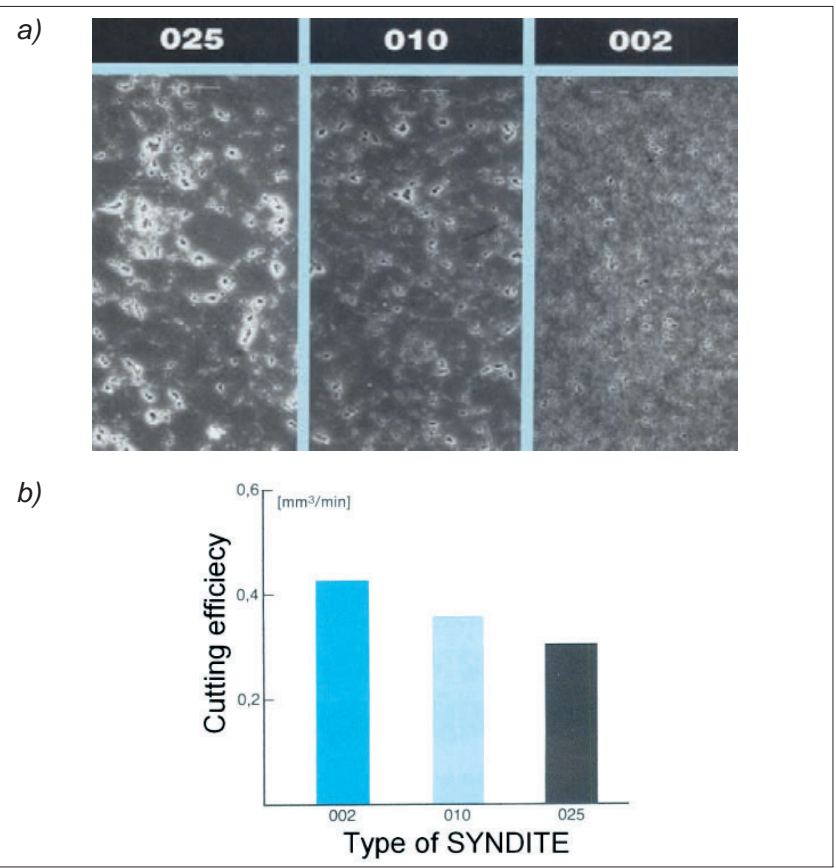

Fig. 3. Size effect of micro diamond grains on practical properties of PCD materials by the example of SYNDITE ${ }^{\mathrm{TM}}$ material manufactured by Element 6: a) sintered construction with three different size micro grains, b) diamond grain size effect on cutting efficiency [11]

PCD materials, or so-called PCBN materials - if using cubic boron nitride grains, are represented by black solids made up of nano- and micro-polycrystals and are similar in structure to natural carbonado diamonds or diamonds obtained in explosive synthesis. The diamond structure is characterized by block isometric construction in the form of aggregate grains and is more resistant to static and dynamic thermal-mechanical loads than mono- and polycrystalline diamonds. The aggregate structure causes, that diamonds show significantly less tendency to crumble up during work and at the same time they expose continuously new vertices and edges, so that the PCD material would not change its cutting properties. The final properties of the sintered materials depend on the size and final condition of the grains and their degree of packing (Fig. 2). Fig. 3 shows the structure of SYNDITE TM ${ }^{\text {com- }}$ posite, which is offered in different shapes (discs, cubes,

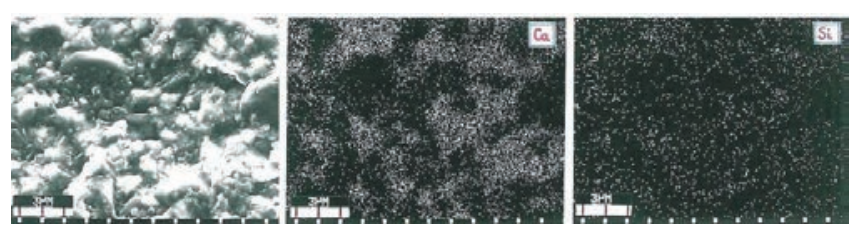

Fig. 4. Structure and distribution $\mathrm{Ca}$ and $\mathrm{Si}$ in Russian monolithic PCD material ARS $-3^{\mathrm{TM}}$

trapezoids etc.) with edges up to tens of millimeters [11]. Fig. 4. shows monolithic material ARS $-3^{\mathrm{TM}}$.

Diamond monolayers, which are used as tools, can also be manufactured by epitaxial methods. The base is a tool body, on which diamonds crystalize and their growth from the gaseous carbon medium with CVD (Chemical Vapour Deposition) methods [26]. Growing abrasive micro grains have a needle-like structure and form a compact unit constructed of many parallel needles of this type.

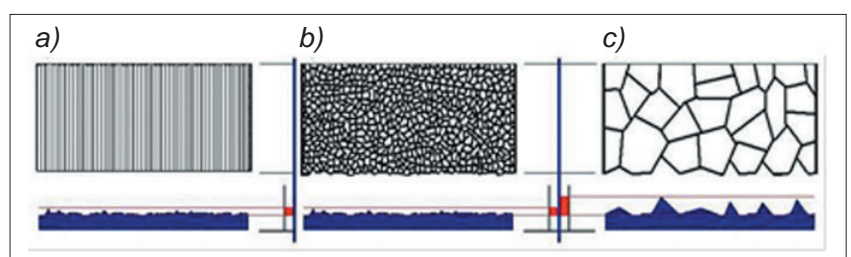

Fig. 5. Arrangements of blades structures: a) diamonds with compact needles structure made in the form of a monolayer using the method CVD, $b$ ) nanodiamonds sintered under high pressure conditions, $c$ ) "popularly used" with sintered carbide or ceramic $[10,24,26]$

Combined structures of nano- and micro-diamonds allow for very precise machining. Due to the hardness of diamonds it is possible to perform cutting operations to relatively large depths, and at the same time it is possible to obtain surfaces with very low values of roughness parameters. Due to large number of micro blades, these highly efficient tools can replace in some operations grinding, lapping and polishing with abrasive wheels or polishing compounds based on polycrystalline and monocrystalline diamond grains (Fig. 5).

\section{Diamond abrasive tools for precision machining}

Diamond abrasive polishing products can be divided into bonded tools, in which individual diamond grains are rigid and permanently bonded to the binder and those using compounds, in which the grains are loosely bound by sticky or solid link.

Used for bonding materials are metals, resins or ceramics. The most popular processes are those of powders metallurgy and electroplated methods, vacuum brazing, or infiltration. Tools with these bondings are used, in particular, for processing stone, ceramics, glass, semiconductors, ect. Tools with thermo or chemosetting resins are used, in particular, for grinding sintered carbides.

The following layout systems can be distinguished: linear (1D), monolayer (2D) and spatial (3D) - Fig. 6, 7.

An example of a tool with linear arrangement of the grains are brushes for bore machining (honing or deburring) [23]. Their characteristic feature is distribution of abrasive grains inside or on the surface of individual fibers. Fibers can be used as single (e.g. wire cutting of honeycomb doors) or combined ones. The final tool manufacturing process (e.g. brushes) involves assembly of diamond loaded fibers into workpiece. Such grinding tools are characterized by considerable flexibility.

The arrangement of grains in a single or several overlapping layers, commonly called as monolayer, is 
a)
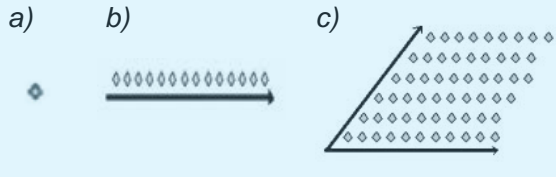

d)

Fig. 6. Layouts of diamonds in tools. Systems: a) OD - one crystal b) $1 \mathrm{D}$ - linear, c) 2D - monolayer, d) 3D - spatial

a)

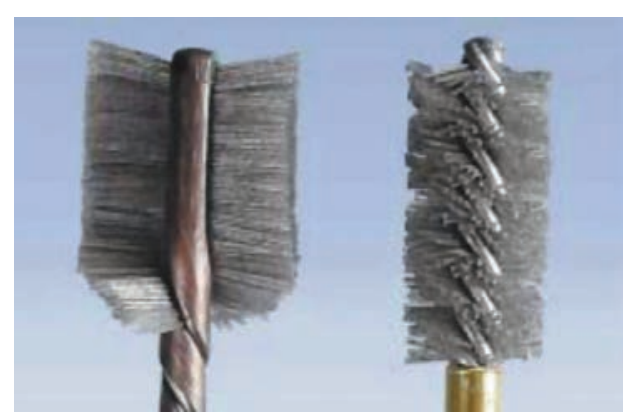

b)

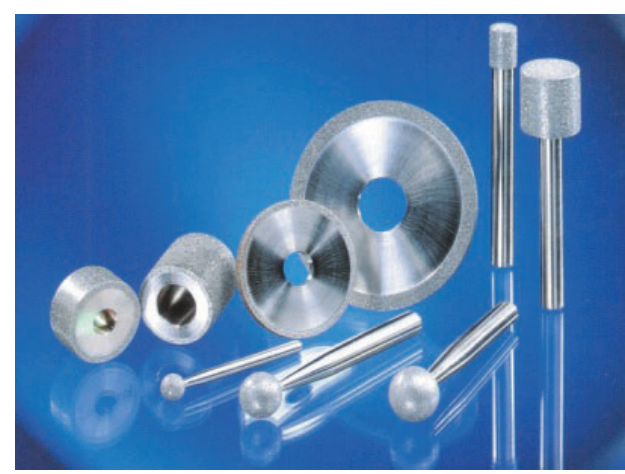

c)

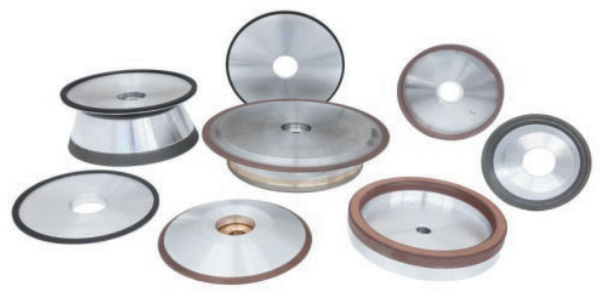

Fig. 7. Examples of diamond composites for polishing operations with different arrangements of diamonds: a) 1D system - brushes to round edges of the bores (e.g. pipes in the fuel apparatus, sockets in the engine, holes in the molds for the manufacture of plastic elements) [23], b) 2D system - diamond saws and cutters used for machining of laminates such as a vehicle body or aircraft fuselage or boats and yacht hulls, c) 3D system - abrasive wheels with resin binder for sharpening of cutting tools or saws with sintered carbide tips [22]

characteristic for diamond tools. There are many structural solutions of such tools. The most common are in the form of grains arranged on surface of a rigid body or, alternatively, as grit tools (grains placed on flexible substrate - e.g. in the form of tape, mesh, sheet, or disc). A specific case is metal foils, which contain microdiamonds inside and are used inter alia for precision machining of molds.

The use of abrasive grains in the form of a monolayer has its advantages and disadvantages. The advantage is that such a system permits formation of larger, often by several times, number of diamond blades on the active surface of the tool - when compared to the tools with grains spatially (3D system) or linearly (1D system) arranged. According to Brugger [12] in the case of 60/80 US mesh grains, the ratio of diamond blades on $1 \mathrm{~cm}^{2}$ of monolayer tool to the number of grains on $1 \mathrm{~cm}^{2}$ of diamond abrasive wheel with a bronze binder equals 181: 41. Another advantage is that the blades are usually „exposed", which protrude above the level of the binder. A relatively "sharper surface" makes the tools most effective in machining multi-phase materials. In particular, it concerns composites which components are characterized by different physicochemical properties, as well as composites with non-homogeneous structure and composed of hard fibers (systems: resin-glass fiber, aramid fiber, carbon fiber or metal fiber) or mineral inclusions (hard grains of oxides and carbides, ceramics, graphite, rocks etc.). In parallel, protruding and sharp grains of monolayer tools are very effective in machining of flexible materials (e.g. rubber and materials for soles), as well as brittle materials (e.g. amber, graphite, rocks).

Monolayer tools obtained from their manufacturers are, most often, ready for work without the need of dressing. Typical rigid bodies, on which diamond monolayers are applied, are made of hardened alloy steels or sintered carbides. The active surface of a monolayer tool is a mapping of its body shape, which in a relatively simple way enables manufacturing of special grinding and polishing tools, for machining of products with complicated shapes. Manufacturing of such tools with grains arranged in 3D system requires use of molds for pressing and additional profiling of the active layer, which would increase production costs and cause losses of the valuable diamond material.

Thickness of the monolayer is primarily determined by the size of the diamonds, which results in that the working elements of the tools could be very small. To this effect tools of this type make the first choice for precision operations such as grinding of profiles or holes with very small diameters as well as for engraving operations.

Monolayer arrangement of diamonds causes that the surfaces of such tools are more abrasion resistant, which predisposes such systems to be used in construction of certain types of dressers, as well as of the machinery elements exposed to abrasion. Fig. 8 shows the surface of the roller dresser [19].

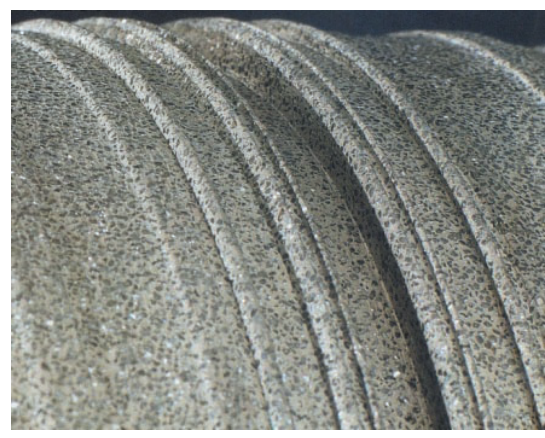

Fig. 8. Example of surface construction of a roller dresser with diamond monolayer [19]

The disadvantage of monolayer composites is the relative thin layer of diamonds, approximately equal to the grain size. Relative efficiency (understood as the volume of grinded material per time unit) of monolayer tools at startup is greater than that of tools with $3 \mathrm{D}$ systems, with machining parameters maintained similar. However, it would relatively quickly decrease following wear of the grains. On the other hand, abrasive tools with 3D structure have initially lower efficiency, but they retain it significantly longer. Thus, they are more competitive in cases, when it is necessary to grind large volumes of material at a time (e.g. cutting out insulation elements made of resin saturated fiberglass).

Tools with diamonds arranged in a 3D system make a group of the greatest value and most popular quantified 
in industrial applications [8, 9, 13, 18-21]. Diamonds may be arranged randomly in space or in a regular manner (e.g. in linear or layer order) and with optimum direction of hardness for individual crystals taken into account. In the case of abrasive tools with 3D system, the content of diamonds is determined by the so-called concentration coefficient. Normally, it is assumed that concentration of $100 \%$ equals $4.4 \mathrm{ct}$ of diamonds in $1 \mathrm{~cm}^{3}$, which means that the volume of diamonds equals $25 \%$ by volume of content in the grinding element. In practice diamond concentration in various tools usually ranges from 25 to 150 depending on the type of abrasive operation. Composites in 3D systems for grinding and polishing operations are used in the form of abrasive wheels (various types of precision grinding of engine blocks and transmission components, fue system components, etc.), hones (cylinders honing, holes machining in different parts of engine and of transmission components), files, saws or drills.

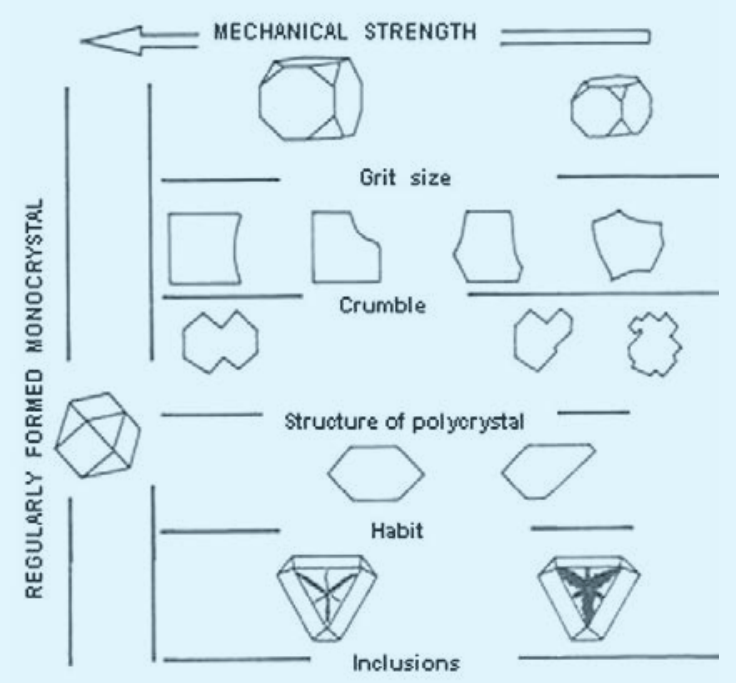

Fig. 9. Mechanical strength of diamonds and their size and internal structure and habit

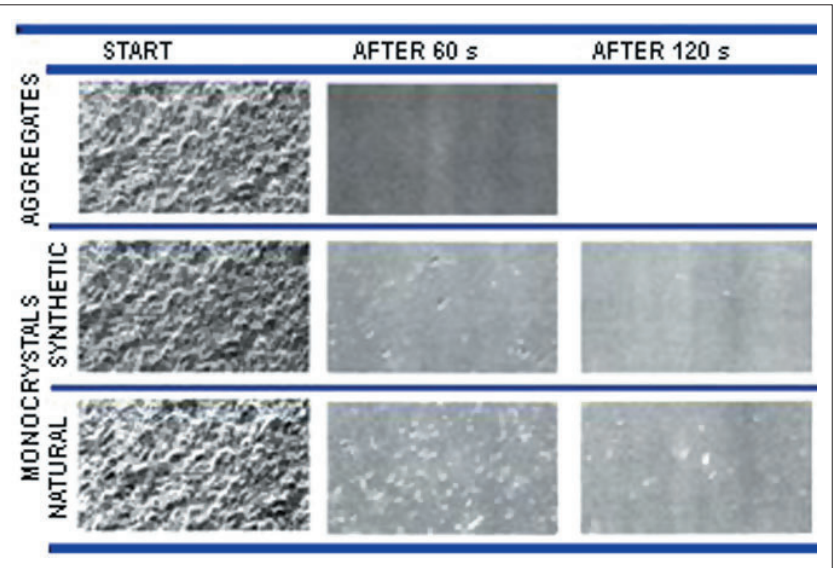

Fig. 10. The effect of polish finish using diamonds of different internal structures. Polished material: sapphire [28]

There is a close relationship between the structure of diamond abrasive particle and its physicochemical and performance characteristics of tools, fig. 9 and fig. 10 [1, $3,4,6]$. In terms of internal structure and habit, the following particle types are distinguished: regularly formed monocrystals, monocrystals developed formless in various directions; polycrystals composed of coarse or fine crystals, aggregate particles. With respect to the surface type the following particle types are distinguished: with plane and smooth faces, with flat and slightly irregular faces, with rough surface, crushed products, ovalized particles. Surfaces of diamond abrasives can be coated with a several microns thick metal $(\mathrm{Ti}, \mathrm{Cr}, \mathrm{Si}, \mathrm{Ni}, \mathrm{Cu})$ or nonmetal layer.

\section{Diamond compounds for lapping}

Composites with diamond grains that are loosely bonded by means of so-called liquid, viscous or solid connectors are used in finishing operations, especially for lapping [27]. They have the form of pastes or suspensions. The content of diamonds ranges from a few to several dozen percent and is decreasing to follow reduction of linear dimensions of the micro grains, to which the surface increases at the same time.

\section{Conclusion}

Globalization as well as automated and mass production industrial environment force a constant drift for cost reduction and repeatability of individual production. Quality of tools affects the speed, cost and precision of the machining operations and their assembly in the device, which would only then credit to the work. Application of diamond tools or alternatively CBN tools, with the structure carefully selected for particular cutting operation or grinding or polishing process, provides an opportunity to make progress in the modern production.

\section{REFERENCES}

1. Bakoń A., Szymański A. "Practical Uses of Diamonds". Londyn-Warszawa: E. Horwood - PWN. 1992.

2. Borkowski J., Szymański, A. "Uses of Abrasives and Abrasive Tools". New York-Warszawa: PWN - Ellis Horwood. 1992

3. Konstanty J. "Powder Metallurgy - Diamond Tools". Oxford: Elsevier. 2005

4. "Handbook of Machining with Grinding Wheels". New York: CRC Press. 2007.

5. Field J.E. "The Properties of Diamond". Oxford: Academic Press. 1979

6. Wilks J., Wilks E. "Properties and Applications of Diamond". London: Butter-Heinemann. 1992

7. Szymański A. "Technical Mineralogy and Petrography. An Introduction for Materials Technology". Amsterdam: PWN - Elsevier. 1989

8. "Technical specification from Wintherthur-Rappold Company". Austria.

9. "Technical specification from Tyrolit Company". Austria

10. Sung J.C., Lin J. "Diamond Nanotechnology". Singapore: Pan Stanford Publishing. 2010

11. "Technical specification from Element Six (previous De Beers) company". Irlandia.

12. Brugger R. "Nickel Plating". Teddington: Robert Draper Ltd. 1970.

13. "Technical specification from Heson Company". Niemcy.

14. "Technical specification from World Superabrasives Company". USA

15. "Technical specification from ABC Warren Superabrasives Company". USA.

16. "Technical specification from China Superabrasives Company". Chiny.

17. "Technical specification from Strauss Company". Izrael.

18. "Technical specification from $3 M$ Company". USA.

19. "Technical specification from Diamant Boart Company". Belgia

20. "Technical specification from Wendt company". Niemcy.

21. "Technical specification from Winter und Sohn Company" Germany.

22. "Technical specification from Asahi Company". Wielka Brytania.

23. "Technical specification from Osborn Company". Niemcy.

24. Jackson M.J., Morrell J.S. "Machining with Nanomaterial". New York: Springer Science + Business Media. 2009.

25. Klocke F., Soo S.L., Karpuschewki B., Webster J.A., Novovic D., Elfizy A., Axinte A., Toenissen S. "Abrasive machining of advanced aerospace alloys and composites". CIPR Annals - Manufacturing Technology. 64 (2015): s. 581-604.

26. Asmussen J., Reinhard D.K. "Diamond Films Handbook". New York: Marcel Dekker Inc., 2002.

27. Barylski A. "Problems of flat surface lapping, Developments in mechanical engineering". Gdańsk: Wydawnictwo Politechniki Gdańskiej. 2005, s. 177-193.

28. "Technical specification from Du Pont Company". USA 